\title{
Adenoid cystic carcinoma of the breast
}

\author{
RICHARD C. JAWORSKI \\ M.B.B.S.
}

KEN L. KNEALE

M.B.B.S., F.R.C.P.A.

ROSS C. SMITH
M.B.B.S. F.R.A.C.S.
The Departments of Anatomical Pathology and Surgery, Concord Hospital, Concord NSW 2139, Australia

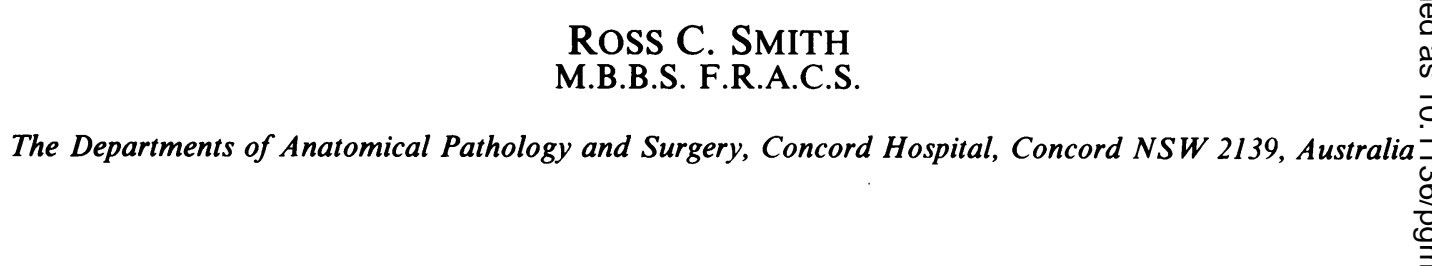

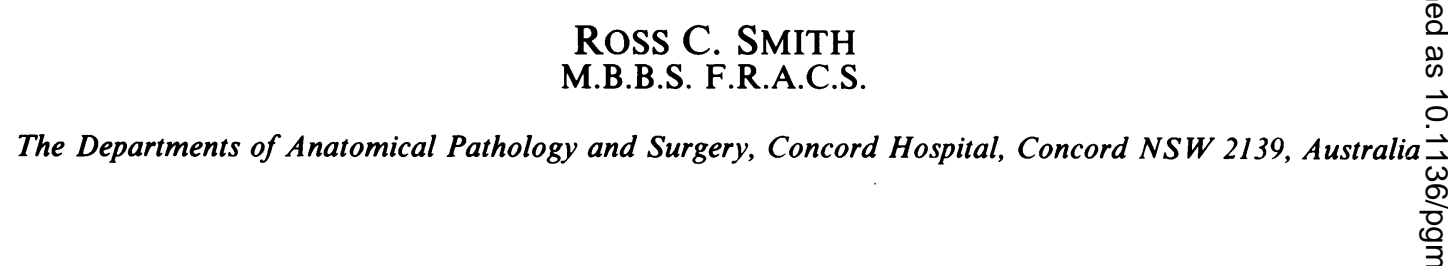

\section{Summary}

\begin{abstract}
Adenoid cystic carcinoma is a rare malignant tumour of the breast. It usually presents as a painful, apparently benign lump near the nipple. The tumour has an interesting histology, natural history and mammographic appearance. Mastectomy is usually curative.
\end{abstract}

KEY WORDS: malignant, adenoid cystic carcinoma, breast.

\section{Introduction}

Adenoid cystic carcinoma is a rare tumour (Anthony and James, 1975) which presents as an apparently benign lesion. In contrast to such tumours occurring in other sites it has a low malignant potential (Anthony and James, 1975; Prioleau et al., 1979; Verani and Bel-Kahn, 1973) and excision would be expected to be curative. We present a case report which illustrates the features of this condition.

\section{Case report}

A 55-year-old woman presented to Concord Hospital with a lump in the right breast. The lesion had been intermittently painful and there was no discharge from the nipple. The lump was first noted nine months previously when she underwent mammography (Fig. 1) and ultrasonography (Figs 2a, b, c) and was advised to have the apparently benign lesion excised. She had had two children, both of whom had been breast fed, and there was no family history of breast disease.

On examination there was a round, smooth, tender mass measuring $1.5 \times 1.0 \mathrm{~cm}$ beneath and medial to the right nipple. Axillary lymph nodes were palpable but on clinical grounds were not thought to contain metastatic tumour. Chest $\mathrm{X}$-ray was normal. In view of the apparently benign nature of the lesion excision biopsy was done without frozen section. Histology showed the lesion to be an adenoid cystic carcinoma
(Fig. 3) that appeared to extend to the line of excision in one area. A subsequent right Patey mastectomy showed no evidence of residual tumour in the breast or lymph nodes.

\section{Discussion}

Adenoid cystic carcinoma of the breast is a rart tumour which has been reported mainly in women between the ages of 31 and 80 years (Anthony Pnes James, 1975). The tumour usually occurs in 7 he region of the nipple (Anthony and James, 1\% Prioleau et al., 1979; Friedman and Oberman, 1970 It is often painful and/or tender and is not associate with a bloody discharge. The clinical features are those of a benign lesion and may be misleading.

Adenoid cystic carcinoma of the breast is though to arise in the major lactiferous ducts (Koss, Branna and Ashikari, 1970). There is controversy as to whether the tumour is predominantly of duct epithelial or of myoepithelial origin (Anthony and James, 1975; Koss et al., 1970; Quizilbash, Patterso and Oliveira, 1977). Histologically, the presence of biphasic cellular and cribriform pattern with the formation of cystic spaces are features characteristig of adenoid cystic carcinoma (Anthony and James 1975; Koss et al., 1970; Friedman and Obermang 1970). Perineural invasion and lack of mitoses cellular pleomorphism and necrosis are addition features (Prioleau et al., 1979; Friedman and Ober man, 1970). On some occasions it may be necessar to distinguish adenoid cystic carcinoma from \& cribriform intraduct carcinoma (Friedman and Obern man, 1970).

These tumours have a better prognosis than counterparts in other sites of the body. Adenoid cystic carcinoma has only once been reported as metastasising to axillary lymph nodes (Verani and Bel-Kahn, 1973). Local recurrence and pulmonary metastases have been reported (Cavanzo and Taylor 


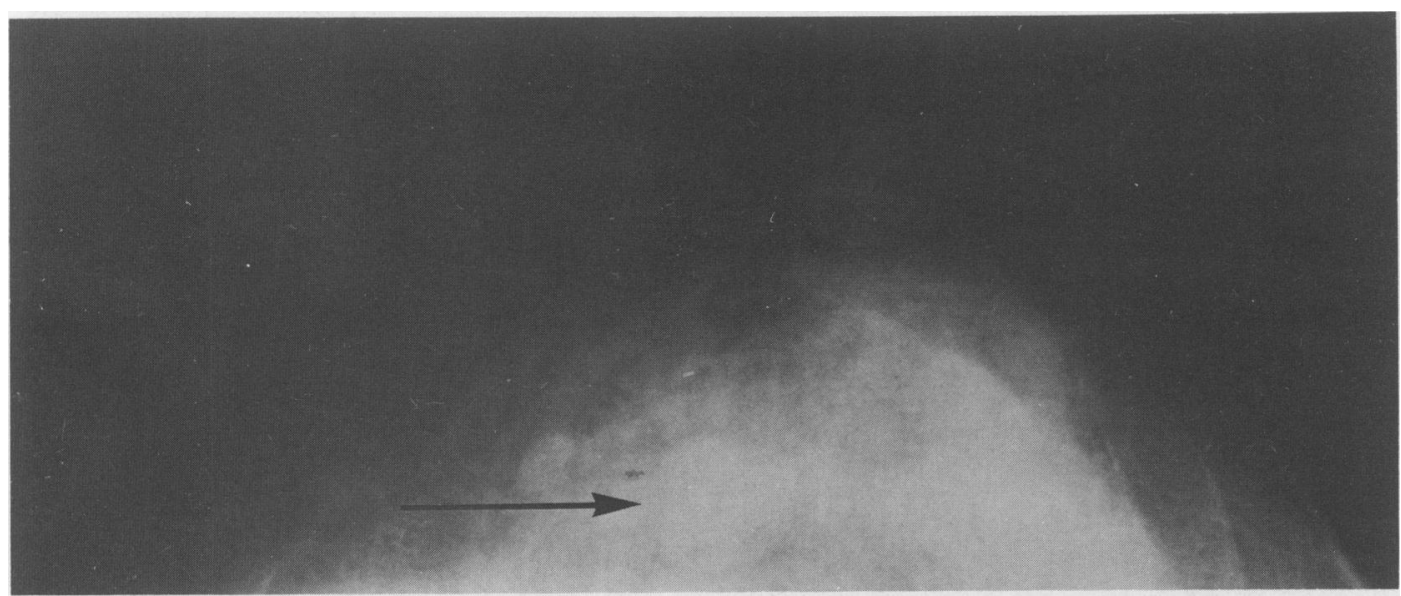

FIG. 1. Mammogram - film. A cranio-caudal view of the right breast showing a well-defined and therefore benign appearing mass medial to the nipple (Arrow). There is a second smaller, more irregular mass slightly more medially and superficially placed.

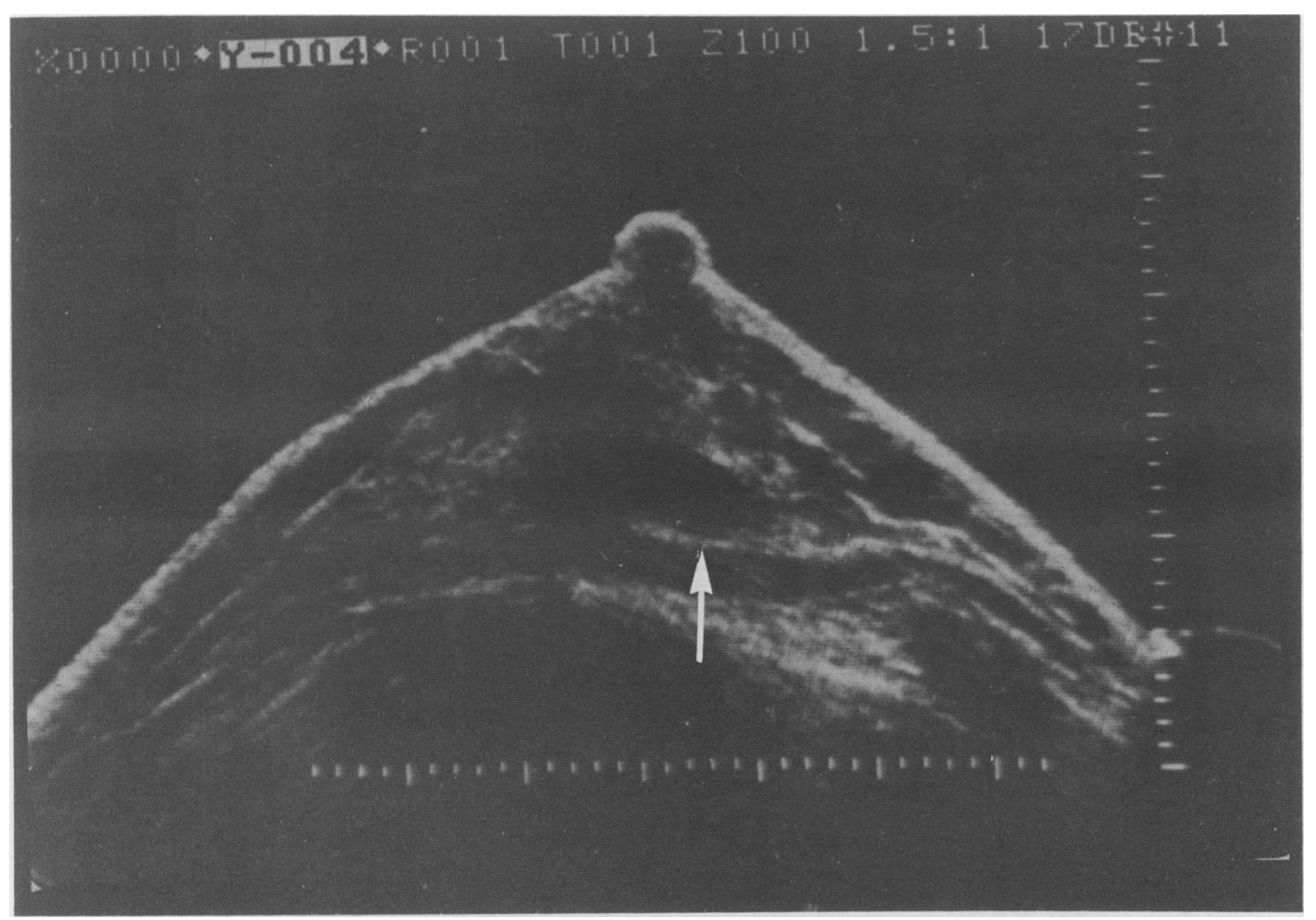

FIG. 2(a). Ultrasound-Compound Scan. Medial to the nipple in the right breast is a $1.5 \mathrm{~cm}$ area without internal echoes deeply placed on the pectoral fascia, with well-defined boundaries. The appearance in this view suggests a cyst. 


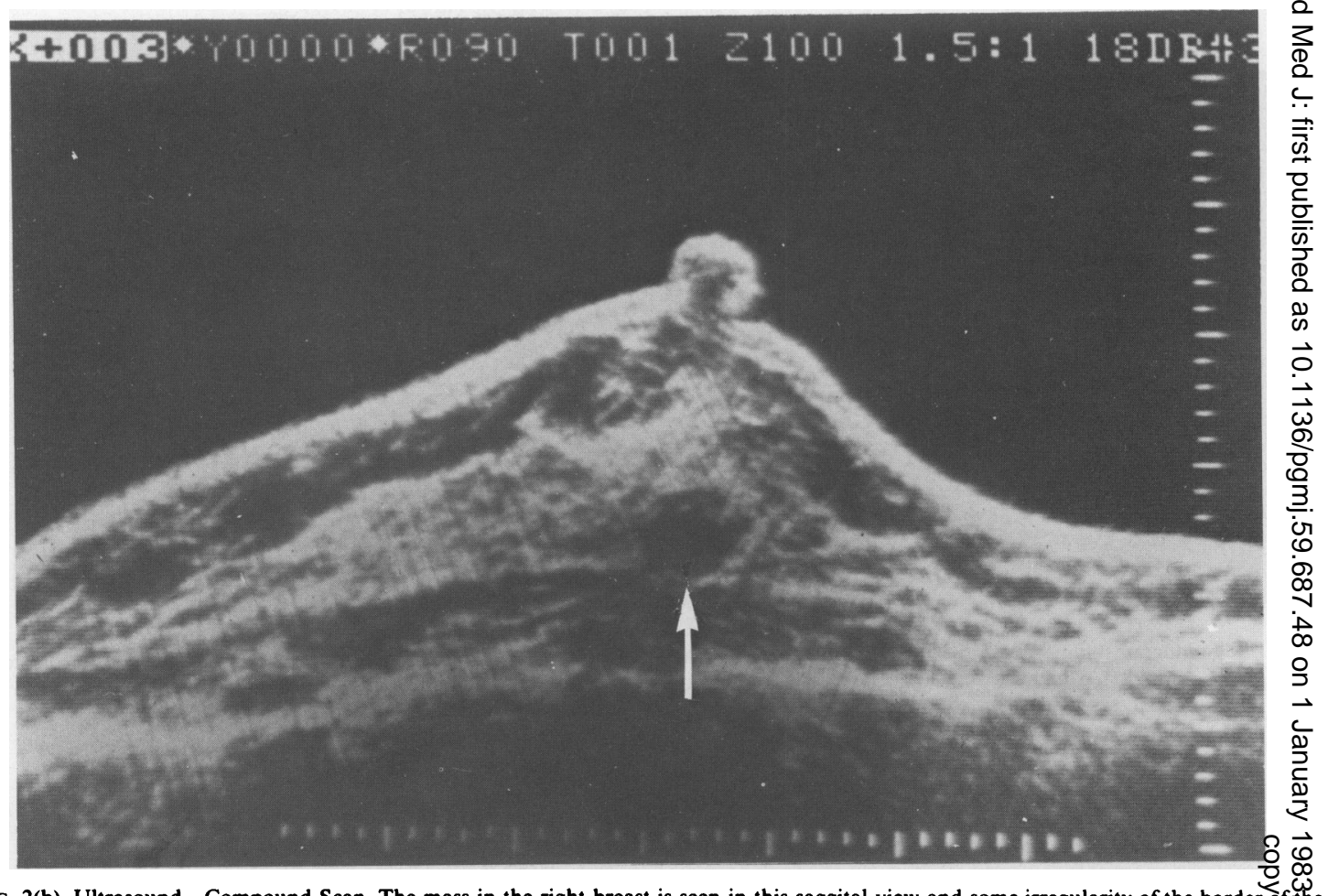

FIG. 2(b). Ultrasound-Compound Scan. The mass in the right breast is seen in this saggital view and some irregularity of the bordersf the anechoic area is displayed.

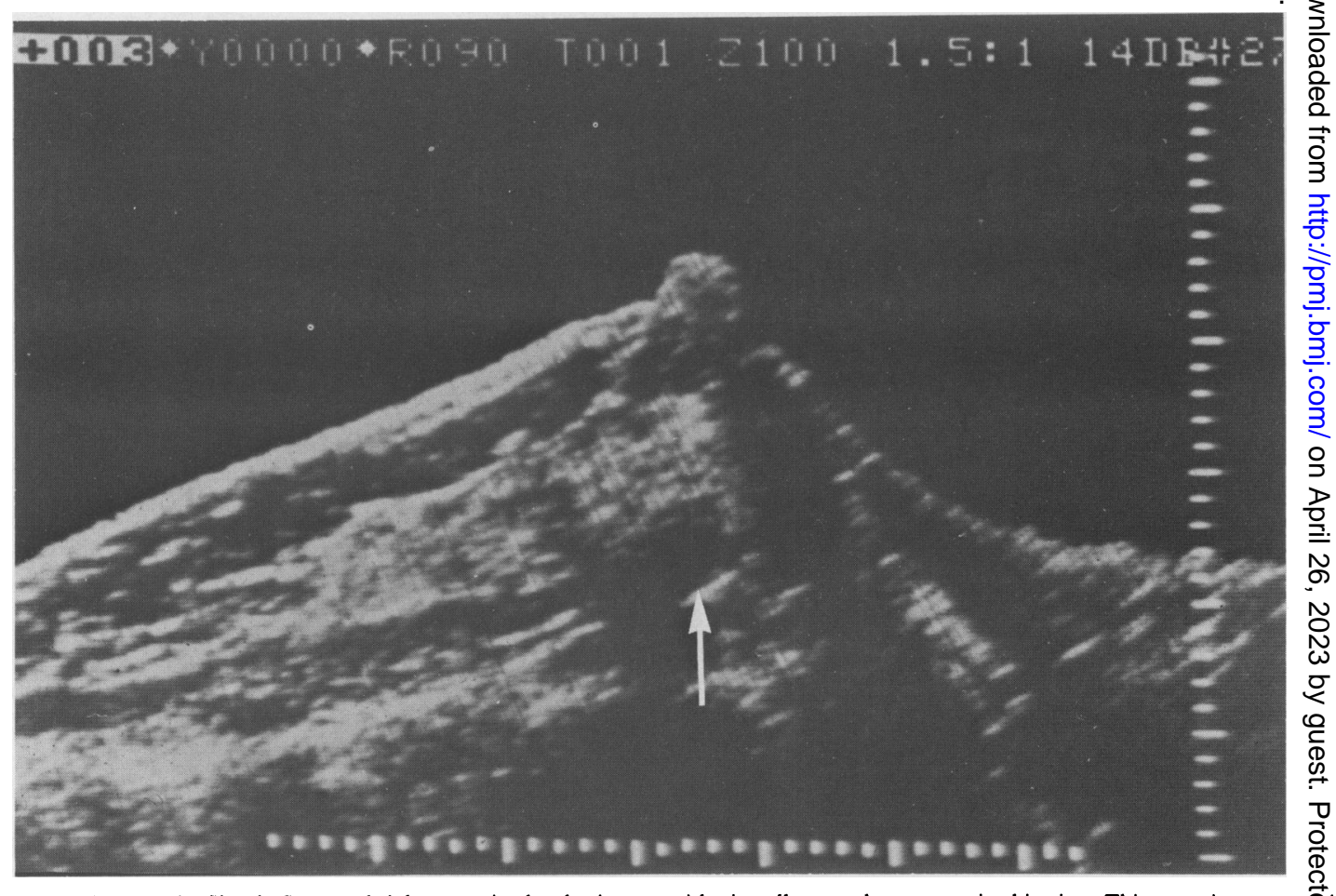

FIG. 2(c). Ultrasound-Simple Scan. A bright posterior border is seen with virtually no enhancement in this view. This sometimes occu满 in simple cystic lesions which are deeply placed. The bright posterior border implies a well defined and usually benign lesion. Howeger, irregularity of the border is a suspicious sign. 


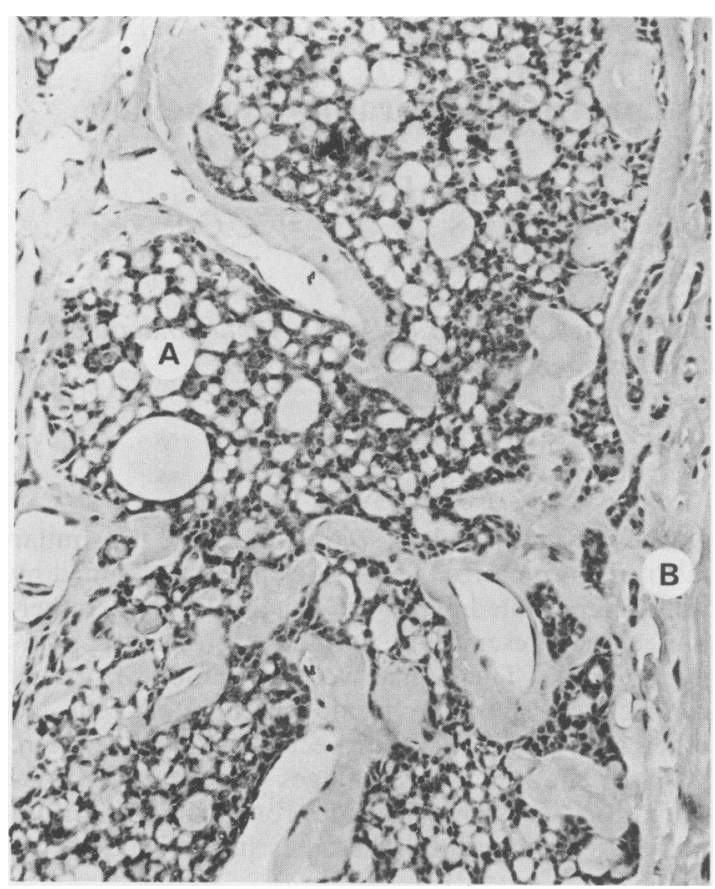

FIG. 3. Light micrograph demonstrating the cribriform pattern (A) and the cylindromatous stroma (B) characteristic of adenoid cystic carcinoma $(\mathrm{HE}, \times 125)$.

1969; Lim, Kovi and Warner, 1979; Nayer, 1957). The reasons for this improved prognosis are unknown. It has been suggested that it may be due to the small size of the tumour at the time of diagnosis or the fact that the tumour may be easily excised, in contrast to tumours of the nasal sinuses, trachea and salivary glands and due to the possibility that adenoid cystic carcinoma of the breast may be a slower growing tumour than when it occurs in other sites (Cavanzo and Taylor, 1969).

The unusual features of adenoid cystic carcinoma of the breast have important implications regarding treatment. Firstly, it presents as a benign breast lesion. Secondly, the histological appearances may be confused with invasive ductal carcinoma and paraffin sections are the preferred method of establishing a diagnosis. Thirdly, because of the low incidence of lymph node and pulmonary metastases, wide local excision or simple mastectomy may be the preferred treatment (Prioleau et al., 1979; Friedman and Oberman, 1970; Cavanzo and Taylor, 1979; Lerner, Molnar and Adam, 1974) although Patey mastectomy is generally recommended when suspicious lymphadenopathy is present. Documentation of cases such as this will help to establish the true incidence and natural history of this unusual condition.

\section{Acknowledgments}

We wish to thank the Sydney Square Diagnostic Breast Clinic for providing ultrasound and mammographic studies and Miss D. Ivers for her typing assistance.

\section{References}

ANTHONY. P.P. \& JAMES. P.D. (1975) Adenoid cystic carcinoma of the breast: prevalence. diagnostic criteria. and histogenesis. Journal of Clinical Pathology, 28, 647.

CAVANZO. F.J. \& TAYloR. H.B. (1969) Adenoid cystic carcinoma of the breast. An analysis of 21 cases. Cancer. 24, 740.

Friedman. B.A. \& ObERMAN. H.A. (1970) Adenoid cystic carcinoma of the breast. American Journal of Clinical Patholog:. 54, I.

Koss, L.G.. BRanNan, C.D. \& ASHIKari. R. (1970) Histologic and ultrastructural features of adenoid cystic carcinoma of the breast. Cancer, 26, 1271.

LERNER. A.G.. MOLNAR. J.J. \& ADAM. Y.G. (1974) Adenoid cystic carcinoma of the breast. American Journal of Surgery, 127, 585.

LIM. S.K.. Kovi. J. \& WARneR. O.G. (1979) Adenoid cystic carcinoma of the breast with metastasis: a case report and review of the literature. Journal of the National Medical Association (Nen York). 71, 329.

NAYER, H.R. (1957) Cylindroma of the breast with pulmonary metastases. Diseases of the Chest. 31, 324.

Prioleau. P.G.. Santa Cruz. D.J.. Buettner. J.B. \& Bauer. W.C. (1979) Sweat gland differentiation in mammary adenoid cystic carcinoma. Cancer, 43, 1752.

Qizilbash. A.H.. Patterson. M.C.\& Oliveira, K.F. (1977) Adenoid cystic carcinoma of the breast. Archives of Pathology and Laboratory Medicine, 101, 302.

VERANI. R.R. \& BEL-KAHN. J. VAN DER (1973) Mammary adenoid cystic carcinoma with unusual features. American Journal of Clinical Pathologi: 59, 653.

(Accepted 27 April 1982) 